\title{
Andamiaje Parental Durante el Visionado Televisivo Conjunto en Madres Costarricenses y sus Hijos Preescolares
}

\author{
Parental Scaffolding During Television \\ Co-Viewing in Costa Rican Mothers and Their Preschoolers
}

\author{
Ana M. Carmiol, Rolando Pérez Sánchez, Adriana Mata Calderón e Isabel Molina Mesén \\ Instituto de Investigaciones Psicológicas, Universidad de Costa Rica
}

\begin{abstract}
Actualmente existen distintas posiciones sobre los efectos del uso de las tecnologías de la información y la comunicación en el desarrollo infantil, aunque poco se conoce sobre su utilización en edades tempranas. Este artículo describe el visionado televisivo en niños y niñas preescolares costarricenses. El Estudio 1 se propuso detallar el contexto de visionado televisivo de niños y niñas en el hogar. Se realizó una encuesta mediante un muestreo por conveniencia a 285 familias de niños y niñas con edades entre 2 y 8 años $(M=5$ años y 2 meses, $D E=12,75$ meses), para lo cual se distribuyó un cuestionario por medio de redes sociales y en cuatro jardines infantiles. Los resultados indicaron que los niños y niñas miran la televisión acompañados por sus padres y madres, quienes reportaron conversar sobre los contenidos de los programas televisivos durante su proyección. Con base en estos hallazgos, el Estudio 2 se propuso caracterizar el andamiaje parental brindado durante el visionado televisivo conjunto. Utilizando un muestreo por conveniencia, se realizaron videograbaciones de 17 díadas madre-hijo ( $M=3$ años y 9 meses, $D E=6,45$ meses) mirando un programa infantil. Los análisis de las interacciones indicaron que las madres conversaban sobre lo proyectado, ofreciendo principalmente descripciones de los contenidos televisivos a través del etiquetado y la descripción de acciones, seguido por evaluaciones de los contenidos del programa y por la formulación de conexiones entre los contenidos del programa y las experiencias del niño. El uso de predicciones e inferencias sobre los contenidos fue escaso. En conjunto, estos resultados brindan información valiosa para el desarrollo de estudios futuros orientados a evaluar el potencial del visionado conjunto para la promoción del desarrollo infantil.
\end{abstract}

Palabras clave: andamiaje parental, desarrollo infantil, televisión, TIC, visionado conjunto

Different perspectives about the impact of early exposure to communication and information technologies are currently available in the literature. However, little is known about the use of these technologies among children. This article describes how Costa Rican preschoolers watch television. Study 1 specifies the context in which children watch television at home. A survey was applied to 285 families with children between 2 and 8 years old $(M=5$ years and 2 months, $S D=12.75$ months) using convenience sampling. Questionnaires were distributed through social networks and in four preschools. Results indicated that children watch television in the company of their parents, who reported talking about the contents of the televised programs with their children. Based on these results, the aim of Study 2 was to characterize the parental scaffolding provided during television co-viewing. Using convenience sampling, video recordings of 17 mother-child dyads $(M=3$ years and 9 months, $S D=6.45$ months $)$ watching a child television program were completed. Videotape analyses indicated that mothers talked to children while watching the program. These conversations mostly described program's content, mainly using labeling and description of actions, followed by evaluations of the program's content and connections between the content and the child's personal experiences. The use of predictions and inferences about the content of the program was scarce. Taken together, these results inform the development of future studies aimed at evaluating the potential of co-viewing to promote child development.

Keywords: parental scaffolding, child development, television, ICT, co-viewing

Ana M. Carmiol iD https://orcid.org/0000-0002-3508-0333

Rolando Pérez Sánchez iD https://orcid.org/0000-0001-6321-2543

Adriana Mata Calderón (iD https://orcid.org/0000-0001-9626-0082

Isabel Molina Mesén (iD https://orcid.org/0000-0001-7334-9594

Isabel Molina Mesén pertenece ahora a la Fundación Omar Dengo, San José, Costa Rica.

Las autoras y el autor agradecen la colaboración de las familias participantes. Esta investigación fue realizada gracias al financiamiento otorgado por la Vicerrectoría de Investigación de la Universidad de Costa Rica a la primera autora y al segundo autor (Proyecto $\mathrm{N}^{\circ}$ 723-B5-315). Las autoras y el autor no presentan conflictos de intereses que revelar.

La correspondencia relativa a este artículo debe ser dirigida a Ana M. Carmiol, Instituto de Investigaciones Psicológicas, Universidad de Costa Rica, Apartado postal 2060, San José, Costa Rica. Email: ana.carmiol@ucr.ac.cr 
Las tecnologías audiovisuales en general y las llamadas tecnologías de la información y la comunicación (TIC) han tenido un avance y una penetración vertiginosa en la vida de las personas. En 2015, alrededor del $90,6 \%$ de la población costarricense entre 18 y 65 años contaba con una línea de teléfono móvil propia, mientras que el 70,8\% contaba con acceso a internet móvil. A pesar del uso creciente de estas tecnologías más recientes, la televisión continúa siendo el medio más popular entre la población al día de hoy. En el año 2015, un 98,6\% de los hogares costarricenses reportó tenencia de al menos un televisor (Ministerio de Ciencia, Tecnología y Telecomunicaciones [MICITT], 2016). Indudablemente, la población infantil se ve expuesta a estas tecnologías, sin que se posea en la actualidad información sobre la frecuencia y los tipos de uso que le dan en el contexto costarricense. El propósito de los dos estudios que aquí se reportan es describir las características del visionado televisivo por parte de niños y niñas preescolares costarricenses. El Estudio 1 tuvo como objetivo principal brindar información sobre las características del contexto en el cual niños y niñas costarricenses en edad preescolar ven televisión en sus hogares.

En la actualidad existen distintas posiciones con respecto a los efectos del uso de las TIC en el desarrollo infantil. La Academia Estadounidense de Pediatría ha enfatizado los efectos perjudiciales de la exposición a las TIC en edades tempranas, por lo que recomienda un uso limitado de la televisión (Reid Chassiakos et al., 2016). En contraste, otros han apuntado a los beneficios de la exposición a pantallas para el desarrollo infantil (Anderson \& Hanson, 2010), señalando que la discusión no es tan simple como solamente determinar una cantidad de tiempo al día para su utilización, enfatizando la necesidad de tomar en cuenta los distintos elementos intervinientes a la hora de considerar los efectos de la exposición en el desarrollo infantil. Paradójicamente, el debate entre estas distintas posiciones no ha partido de una clara caracterización de cómo utilizan los niños y las niñas las TIC en el contexto familiar, lo cual facilitaría dar sustento basado en evidencia a la identificación más precisa de oportunidades y riesgos en el uso de estas tecnologías.

La evidencia que señala efectos negativos de la exposición a la televisión en niños y niñas se enfoca principalmente en la cantidad de tiempo que estos ven la televisión (Kostyrka-Allchorne et al., 2017; Lin et al., 2015) y no en comprender y caracterizar la calidad en la exposición. Otras investigaciones han planteado que lo más importante es precisamente la calidad del andamiaje parental que se recibe mientras se ve la programación (Blankson et al., 2015; Linebarger et al., 2014). A la luz de lo anterior, el Estudio 2 que aquí se reporta tuvo como fin brindar información sobre la calidad del andamiaje parental al que se ven expuestos niños y niñas durante el visionado televisivo conjunto.

\section{Calidad del Visionado Televisivo: El Rol del Andamiaje Parental}

La calidad del visionado televisivo conjunto depende principalmente del andamiaje dado por los cuidadores a los niños y las niñas. En términos generales, el andamiaje se define como el conjunto de estrategias utilizadas por el adulto para facilitar y posibilitar que el niño desarrolle una destreza o habilidad, o bien resuelva una tarea. En el contexto del presente estudio, el andamiaje se entiende como el conjunto de estrategias discursivas utilizadas por los adultos para facilitar en los niños y niñas la capacidad de centrar su atención en la televisión y comprender el contenido televisivo (Barr et al., 2008).

Las figuras cuidadoras difieren en la estructura del andamiaje parental que utilizan al interactuar con niños y niñas. En el contexto de la reminiscencia o conversación sobre eventos personales pasados, la evidencia señala que padres y madres utilizan al menos uno de dos tipos de andamiaje parental (Carmiol \& Sparks, 2014; Fivush \& Fromhoff, 1988; McCabe \& Peterson, 1991). Uno de ellos se refiere al estilo altamente elaborado, donde las personas cuidadoras facilitan la participación infantil en la reconstrucción del evento pasado. Para esto, utilizan preguntas abiertas (e.g., "¿Qué?", "¿Cómo?", "¿Por qué?") y confirman las contribuciones del niño o niña. A diferencia, otros adultos utilizan un estilo poco elaborado de conversación, caracterizado por un uso limitado de preguntas, que en su mayoría son cerradas y que repiten durante la conversación en su intento de conseguir respuestas específicas por parte del niño o niña. Además, múltiples hallazgos señalan una relación positiva entre el uso de un estilo de conversación altamente elaborado y distintos logros del desarrollo temprano (Waters et al., 2019).

Diferencias individuales también han sido identificadas en el contenido del andamiaje parental, específicamente en lo que se refiere a su demanda cognitiva hacia el niño y la niña. DeTemple (2001) analizó las conversaciones durante lectura compartida entre madres y niños estadounidenses en una muestra de estratos socioeconómicos bajos. Al leer el libro, las madres realizaron preguntas y comentarios sobre las imágenes y palabras expuestas la mayor parte del tiempo (43\% al 60\%), por lo que llamó a estas estrategias como habla sobre el contexto inmediato. En menor medida, observó que las madres utilizaron el texto o las 
ilustraciones en el libro como un trampolín para referirse a experiencias personales del niño, comentarios o preguntas de conocimiento general, o bien para hacer predicciones e inferencias sobre el texto (11\% a $18 \%$ ), y denominó estas estrategias como habla sobre el contexto no inmediato.

La calidad del contenido del andamiaje parental también se ha analizado en el contexto de conversaciones orientadas a resolver tareas del orden físico, como comprender el funcionamiento de un objeto poco familiar. Los hallazgos disponibles se asemejan a los observados en el contexto de la lectura compartida: en la mayoría de los casos, las personas cuidadoras utilizan estrategias de bajo nivel de abstracción, como describir el objeto. Estrategias de mayor complejidad, como explicaciones causales sobre el funcionamiento de este, o bien conexiones entre el objeto y el conocimiento previo del niño o niña (Crowley et al., 2001), son también poco frecuentes. En conjunto, los hallazgos de estas distintas investigaciones previas sugieren que el andamiaje parental caracterizado por un mayor uso de estrategias discursivas abstractas, donde se utiliza lenguaje descontextualizado, se relaciona con mayores ganancias cognitivas y de aprendizaje por parte de niños y niñas (Benjamin et al., 2010; Fender \& Crowley, 2007; Tompkins et al., 2017).

En el contexto específico del visionado televisivo, Barr et al. (2008) estudiaron la relación entre el andamiaje parental y la capacidad de infantes entre 12 y 18 meses de edad para atender a programas infantiles de televisión (e.g., Baby Einstein). Entre sus resultados, se encontró una asociación entre el uso de andamiaje materno de calidad y la atención puesta por el infante al contenido televisivo. Este andamiaje estuvo conformado por el uso de preguntas, etiquetado de acciones y personajes y abstracciones. Estas últimas consistían en segmentos de información ofrecidos por la cuidadora, que se extendían más allá del contenido televisivo (e.g., conectar lo observado con alguna experiencia previa del niño).

La presencia de personas cuidadoras durante el visionado televisivo también influye en las habilidades de procesamiento de la información televisiva de niños y niñas de mayor edad. Al observar un programa de televisión, niños y niñas entre 6 y 13 años de edad asignaron una mayor cantidad de recursos cognitivos, que facilitan la comprensión del contenido televisivo, cuando alguno de sus padres vio el programa con ellos que cuando lo vieron en solitario (Rasmussen et al., 2017). Esto podría explicarse porque los padres son capaces de dirigir la atención de los niños hacia la televisión y brindar un aporte verbal, el cual puede mejorar la capacidad del niño y niña para procesar contenido televisado durante el transcurso de un programa. Es decir, el andamiaje que dan los padres cuando se está observando el programa va a ser un recurso esencial para que los hijos e hijas puedan realizar las inferencias necesarias de los mensajes recibidos (Fidler et al., 2010).

La participación activa de los cuidadores durante el visionado conjunto también se ha encontrado efectiva en la reducción del déficit de transferencia del aprendizaje observado en los niños. Este se refiere a la mayor dificultad que se enfrenta durante la niñez al intentar aprender algo a partir de la observación en una pantalla, en comparación con la experiencia real. Cuando en el visionado conjunto los padres ofrecen andamiaje a través del señalamiento de los objetos físicos que aparecen en la pantalla, niños y niñas de 2 años de edad logran transferir el significado de los nombres de los objetos mostrados en la pantalla a la vida real. Lo hacen con mayor facilidad al contar con este tipo de andamiaje parental que al observar el etiquetado de los objetos por parte de una actriz en la misma pantalla (Strouse \& Troseth, 2014). Además, la utilización de señales visuales y verbales por parte de los padres (e.g., mostrar físicamente el objeto que está siendo proyectado o hacer preguntas sobre el contenido televisivo) y el visionado repetido de un mismo programa disminuye dicho déficit, permitiendo que los niños y niñas puedan aprender a partir de lo que están observando en la pantalla (Barr, 2013; Crawley et al., 1999; Linebarger \& Piotrowski, 2009).

\section{Exposición a la Televisión y Desarrollo Infantil}

Respecto a las características del uso, Lauricella et al. (2015) estudiaron la utilización de cuatro plataformas digitales (la televisión, la computadora, los teléfonos inteligentes y las tabletas) en niños y niñas estadounidenses entre 0 y 8 años. También investigaron su relación con el uso de la tecnología y las actitudes hacia ella desde la perspectiva de los padres y madres. Sus resultados indicaron que el $99 \%$ de las familias tenía al menos un televisor. El tiempo reportado de uso de la televisión por parte de niños y niñas fue el más alto en comparación con las otras tecnologías, con una media de 1,75 horas al día. Además, los padres reportaron una actitud más positiva (e.g., considerar que puede ser una buena herramienta de aprendizaje) hacia el uso de la televisión, por lo que se encontró una correlación positiva entre las actitudes de los padres y el tiempo de uso de los niños y niñas. 
En la edad preescolar ya es posible identificar la instauración de una serie de prerrequisitos asociados a la infraestructura cognitiva y emocional que permiten el visionado televisivo y su comprensión (Van Evra, 2004). Niños y niñas preescolares ya muestran preferencias por los contenidos audiovisuales, que inicialmente se restringían a sonidos, colores o imágenes, y posteriormente se concretan en programas televisivos específicos, como es el caso de las series de televisión (Valkenburg, 2004). Al final de los años preescolares son capaces de comprender producciones narrativas directas con tramas razonablemente lineales que incorporan acciones concretas (Anderson \& Hanson, 2010).

La calidad de los programas de televisión que ven los niños y niñas también afecta su desarrollo. Por ejemplo, el tiempo que el niño utiliza viendo programas educativos (e.g., Plaza Sésamo) es un predictor positivo de calificaciones en la secundaria, así como también otras medidas de comportamiento en la adolescencia (Anderson \& Hanson, 2010). Además, el visionado de programas con una historia no estructurada y que no proveen muchos ejemplos de lenguaje de calidad predicen habilidades lingüísticas pobres, mientras que programas que estimulan el desarrollo del lenguaje a través de un etiquetado claro, el uso de vocalizaciones alentadoras e interacciones con los personajes de la pantalla están asociadas con resultados positivos en lenguaje (Kostyrka-Allchorne et al., 2017). Hsin et al. (2014) encontraron que el contenido de los programas y la forma en que se abordan las temáticas pueden predecir un mejor aprendizaje o asociarse con conductas agresivas. Estos autores destacan que es muy importante que el contenido sea adecuado a la edad de los niños y niñas.

Observar programas televisivos con contenido educativo de alta calidad puede promover en los niños y niñas el aprendizaje de conceptos académicos y mejorar las capacidades en habilidades complejas, siempre dependiendo de las habilidades previas (Kostyrka-Allchorne et al., 2017). Al respecto, se ha encontrado que población escolar en riesgo social puede aumentar su rendimiento en funciones ejecutivas a partir de la exposición a programas televisivos educativos (Linebarger et al., 2014). También se ha demostrado que niños y niñas de 18 meses de edad pueden recordar y realizar acciones aprendidas de un vídeo después de dos semanas, mientras que los de 24 meses pueden recordarlas hasta cuatro semanas después (Brito et al., 2012).

Revisiones sistemáticas han encontrado que la mayoría de las investigaciones relaciona el uso de tecnologías con el aprendizaje en el dominio cognitivo (e.g., lenguaje y alfabetización, matemáticas, memoria, ciencias), así como con los ámbitos social y emocional (e.g., trabajo colaborativo, autorregulación emocional). Sin embargo, hacen énfasis en que este aprendizaje no se da por sí solo, sino que depende de variables como la relación entre la edad de los niños y los contenidos, sus experiencias previas, la duración del tiempo de uso y el acompañamiento de personas adultas (Hsin et al., 2014).

A la luz de la gran cobertura televisiva existente en la actualidad en Costa Rica (MICITT, 2016) y en otros países latinoamericanos (Gobbi \& Machado Filho, 2015) y del creciente uso de pantallas en la infancia, ya sea a través de dispositivos móviles o de la televisión, y considerando la información actualmente disponible sobre el visionado televisivo en otras latitudes, este trabajo se propuso abordar las siguientes preguntas de investigación:

1. ¿Qué/cómo/cuánto y con quién ven televisión niños y niñas costarricenses en edad preescolar?

2. ¿Cómo se caracteriza la participación de la persona cuidadora y de niños y niñas preescolares a la hora de ver conjuntamente una serie de televisión infantil?

Para responderlas, se procedió a realizar dos estudios descriptivos. El Estudio 1 abordó la primera pregunta de investigación, para lo cual se realizó una encuesta sobre el uso de TIC a los cuidadores y cuidadoras de niños y niñas matriculados en centros educativos preescolares ubicados en zonas urbanas de San José, Costa Rica. El Estudio 2 abordó la segunda pregunta de investigación, para lo cual un grupo de niños y niñas fueron grabados en vídeo con sus madres mientras observaban un programa televisivo. El análisis de las videograbaciones se centró en identificar y cuantificar las estrategias discursivas utilizadas por las madres, los niños y las niñas durante el visionado televisivo, tanto a nivel de estructura como a nivel de contenido. 


\section{Estudio 1}

\section{Método}

\section{Participantes}

La muestra incluyó 285 familias de niños y niñas con edades entre 2 años 2 meses y 8 años 1 mes (edad media $=5$ años 2 meses, $D E=12,75$ meses, rango $=26-97$ meses). La muestra incluyó cuatro niños y niñas mayores de 7 años (de 85, 86, 88 y 97 meses). A pesar de su edad, se mantuvieron incluidos en el análisis, pues, según el reporte paterno y materno, cumplían los criterios de inclusión. Además, las tendencias de los resultados no variaron al excluirlos.

Se recurrió a un muestreo no probabilístico por conveniencia, tomando como fuentes de recolección redes sociales y cuatro jardines infantiles. El 14\% de la muestra se captó por medio de redes sociales, al llenar una versión en línea del instrumento $(n=40)$, luego de que este fuera anunciado en las plataformas en redes sociales del Instituto de Investigaciones Psicológicas de la Universidad de Costa Rica. El restante 86\% de las familias que conformaron la muestra se contactó a través de jardines infantiles y guarderías públicas y privadas ubicadas en la provincia de San José $(n=245)$. La selección de los centros se realizó por conveniencia. Para el contacto de esta muestra, se solicitó la autorización de las directoras de los centros educativos para poder contactar a las familias. Estas completaron el instrumento en papel y lápiz.

En la mayoría de los casos, fue la madre del niño o la niña quien completó el cuestionario $(n=236,82,81 \%)$ y, en menor medida, el padre $(n=26,9,12 \%)$. En el 8,07\% de los casos restantes $(n=23)$ no se indicó quién respondió el cuestionario. Para este estudio, los criterios de inclusión utilizados fueron los siguientes: (a) que el niño o niña asistiera a un centro educativo preescolar y (b) que no presentara ningún diagnóstico médico de dificultades del desarrollo, según lo especificado en la convocatoria de la invitación a llenar el cuestionario. Como se observa en la Tabla 1, la mayoría de la muestra incluyó madres que contaban con secundaria completa y, en menor medida, madres con estudios universitarios o técnicos.

Tabla 1

Estadisticas Descriptivas de las Variables Sociodemográficas de la Muestra del Estudio 1

\begin{tabular}{cc}
\hline \multicolumn{1}{c}{ Variable } & Frecuencia (porcentaje) \\
\hline Sexo del niño & $285(100)$ \\
Femenino & $130(45,6)$ \\
Masculino & $148(51,9)$ \\
No responde & $7(2,5)$ \\
Nivel educativo de la madre & $285(100)$ \\
Primaria completa & $45(15,7)$ \\
Secundaria completa & $153(53,6)$ \\
Estudios técnicos & $10(3,5)$ \\
Estudios universitarios & $77(27,2)$ \\
Personas con las que vive el niño & $285(100)$ \\
Con la madre & $279(97,8)$ \\
Con el padre & $222(77,8)$ \\
Con hermanos mayores & $89(31,2)$ \\
Con hermanos menores & $82(28,7)$ \\
Condición laboral de la madre & $279(100)$ \\
Trabaja fuera de la casa & $209(74,9)$ \\
No trabaja fuera de la casa & $70(25,1)$ \\
Estado laboral del padre & $270(100)$ \\
Trabaja fuera de la casa & $265(98,1)$ \\
No trabaja fuera de la casa & $5(1,9)$ \\
\hline
\end{tabular}

${ }^{1}$ Categorías no excluyentes. 


\section{Instrumento}

Para este estudio se desarrolló el cuestionario de autorreporte titulado Uso de TIC en Niños y Niñas Preescolares, utilizando el criterio de tres expertos con el fin de asegurar su calidad.

Se solicitó a las personas participantes tener en mente un día común, mientras el niño o niña se encontraba en el hogar, a la hora de responder las preguntas.

Con el propósito de conocer la ecología digital en la que se desenvuelven los niños y las niñas, el cuestionario solicitó información sobre la frecuencia de uso de tres distintas tecnologías (televisión, computadora y tableta o celular) y el contexto de uso de cada una. Dado el propósito de esta investigación, los resultados solamente incluyen información concerniente al uso de la televisión.

Los aspectos abordados en las 28 preguntas del cuestionario fueron: (a) intensidad de uso, solicitando especificar la cantidad de minutos al día que el niño o niña utilizaba cada dispositivo, durante la mañana, tarde y noche, de lunes a domingo; (b) frecuencia de uso de canales de televisión específicos (e.g., Disney Junior, Cartoon Network); (c) frecuencia de consumo de tipos distintos de programas televisivos (e.g., dibujos animados con personajes humanos, dibujos animados con personajes animales); (d) frecuencia de uso de distintas aplicaciones para computadora o dispositivo móvil (e.g., juegos, YouTube, aplicaciones educativas); (e) frecuencia con que el niño o la niña utilizaba los distintos dispositivos estando acompañado, (f) frecuencia con que distintas personas (e.g., madre, padre, ambos, hermanos o hermanas) acompañaban al niño o niña mientras usaba cada uno de los dispositivos; (g) frecuencia con la que el padre o madre practicaba distintas acciones de acompañamiento durante el uso conjunto de los dispositivos (e.g., acompañar sin hablar o jugar con ella o él, conversar con él o ella sobre el contenido del programa, jugar con él o ella sobre cosas del programa mientras lo ven) y (h) los tres programas de televisión, las tres aplicaciones de computadora y las tres aplicaciones de tableta o teléfono preferidas por el niño o la niña. Al final del cuestionario se solicitó, además, información sociodemográfica de la persona que lo completó (edad, nivel educativo, relación con el niño o niña) y del niño o niña (sexo, fecha de nacimiento y nivel de educación preescolar). En la mayoría de los ítems se utilizó una escala Likert de 5 puntos, desde 1 (nunca o nada) a 5 (siempre o demasiado).

\section{Procedimiento}

La recolección de datos tuvo lugar entre marzo y octubre del año 2015, luego de obtener el visto bueno del Comité Ético-Científico de la Universidad de Costa Rica.

En su primera sección, el cuestionario incluyó un consentimiento informado que describió el objeto de estudio en un lenguaje accesible, especificó la voluntariedad de la participación y aseguró el manejo confidencial de los datos. El cuestionario fue anónimo, pues no solicitó el nombre de personas cuidadoras, niños o niñas.

Una vez obtenida la autorización de las instituciones educativas, se envió el cuestionario y una invitación escrita a las familias para participar en el estudio, a través del cuaderno de comunicaciones de los niños y niñas. Aquellas familias que decidieron participar enviaron el consentimiento informado firmado y el cuestionario completo de regreso al centro educativo, el que posteriormente fue recolectado por el equipo investigador.

\section{Análisis de Datos}

Se realizaron análisis estadísticos descriptivos. Al revisar los cuestionarios, se observaron valores perdidos en algunas preguntas. Por tanto, las frecuencias varían en los resultados.

\section{Resultados}

\section{¿Qué Ven en Televisión Niños y Niñas Costarricenses en Edad Preescolar?}

La exploración sobre los contenidos televisivos vistos por los niños y las niñas se dio a través de la pregunta ¿Qué tanto le gusta a su hija o hijo cada uno de los siguientes tipos de series, películas o programas de televisión? Como se observa en la Tabla 2, las personas cuidadoras reportaron distintos tipos de contenidos televisivos para los niños preescolares. Sin embargo, el tipo de programa de preferencia se refiere a los dibujos animados con personajes animales, seguido por dibujos animados con personajes humanos. La frecuencia de programación adulta fue menor en esta muestra. 
Tabla 2

Reporte sobre la Frecuencia Promedio de Tipos de Programas Observados por los Niños y Niñas

\begin{tabular}{lccc}
\hline \multicolumn{1}{c}{ Tipo de contenido televisivo } & Media & $D E$ & Rango \\
\hline Dibujos animados con personajes animales $(n=275)$ & 3,99 & 0,74 & $1-5$ \\
Dibujos animados con personajes humanos $(n=276)$ & 3,62 & 1,02 & $1-5$ \\
Programas o documentales de animales $(n=273)$ & 2,98 & 1,12 & $1-5$ \\
Películas o programas con personajes humanos reales $(n=266)$ & 2,91 & 1,09 & $1-5$ \\
Programación adulta $(n=243)$ & 1,39 & 0,69 & $1-5$ \\
\hline
\end{tabular}

Además, se solicitó el reporte de los canales de televisión vistos por los niños y las niñas. Las mayores frecuencias de visionado corresponden a canales de televisión por cable dirigidos a población infantil, como Disney Junior ( $n=267, M=3,93, D E=1,02)$, Discovery Kids $(n=258, M=3,04, D E=1,23)$ y Disney Channel ( $n=249, M=2,42, D E=1,31$ ), mientras que el visionado de programación infantil en canales nacionales reporta una de las frecuencias más bajas ( $n=242, M=1,49, D E=0,83)$.

\section{¿Cuánto Ven Televisión Niños y Niñas Costarricenses en Edad Preescolar?}

Las madres y padres indicaron la cantidad de minutos que el niño y la niña ven televisión en la mañana, tarde y noche, para cada uno de los días de la semana. Como se observa en la Figura 1, la cantidad de tiempo dedicado al visionado televisivo es menor entre los días lunes y viernes y mayor durante los sábados y domingos.

\section{Figura 1}

Minutos Promedio Reportados por la Madre en los que el Niño o Niña Ve la Televisión durante la Semana $(\mathrm{n}=285)$

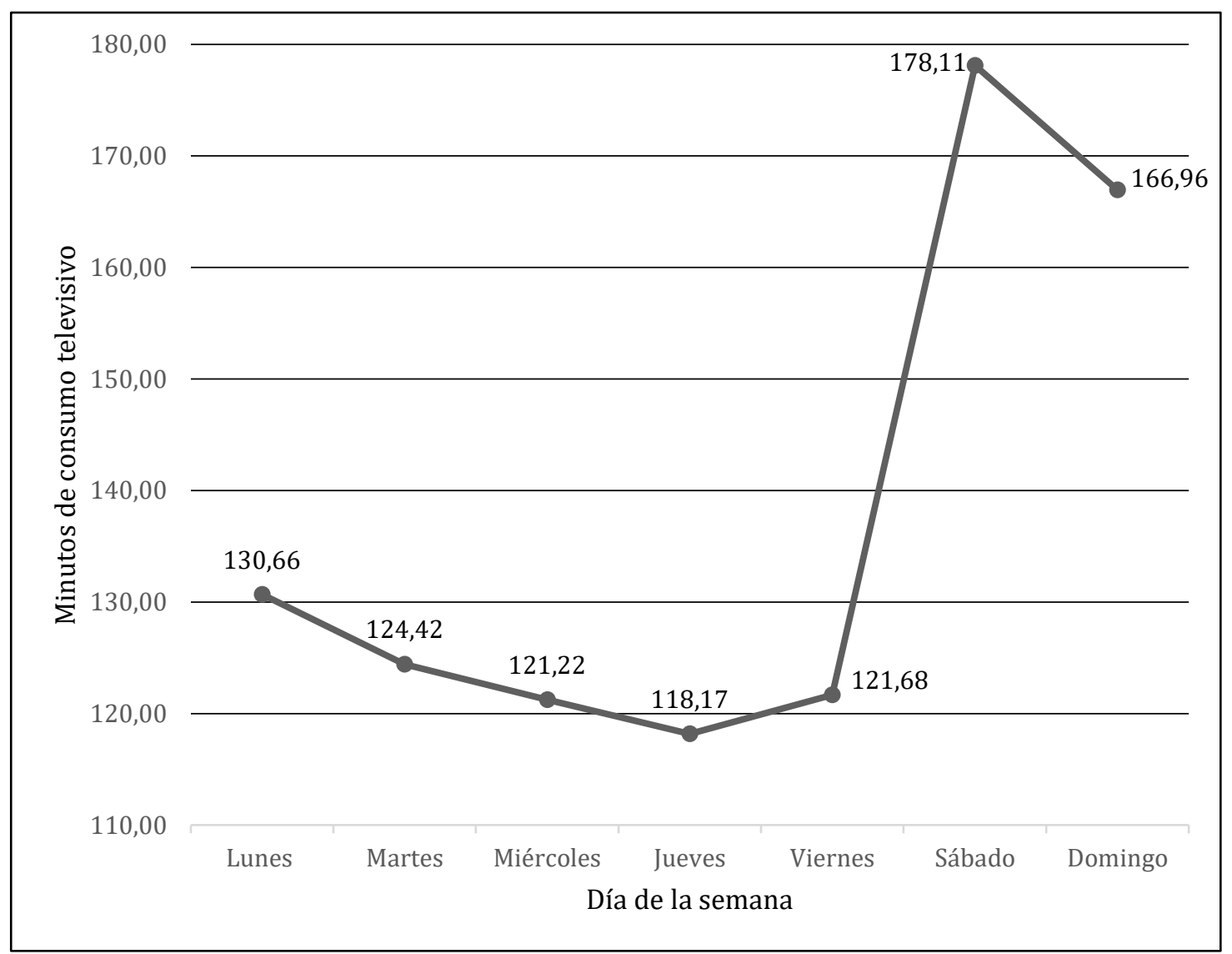




\section{¿Con Quién Ven Televisión Niños y Niñas Costarricenses en Edad Preescolar?}

Para explorar el contexto del visionado televisivo por parte de los niños y niñas, se solicitó a la persona cuidadora indicar la frecuencia en la que el niño miraba la televisión acompañado $(n=278)$. En promedio, las madres respondieron que los niños casi siempre miraban la televisión acompañados $(n=278, M=4,12$, $D E=0,79)$. En la Tabla 3 se observa que los progenitores son las personas reportadas que más frecuentemente acompañan al niño y niña durante el visionado televisivo, seguido por otros familiares, y en menor medida otra persona adulta no familiar. En promedio, las familias participantes indicaron que los niños casi nunca ven televisión en solitario.

Tabla 3

Frecuencia Promedio con que Distintas Personas Miran la Televisión con el Niño y Niña

\begin{tabular}{lccc}
\hline \multicolumn{1}{c}{ Persona que mira la televisión con el niño o niña } & Media & $D E$ & Rango \\
\hline Solo con la madre $(n=261)$ & 3,70 & 0,93 & $1-5$ \\
Solo con el padre $(n=249)$ & 3,11 & 1,07 & $1-5$ \\
Con la madre y el padre $(n=245)$ & 3,07 & 1,14 & $1-5$ \\
Con otro familiar (abuelo/as, tíos, etc.) $(n=246)$ & 2,91 & 1,16 & $1-5$ \\
Con hermanos/as $(n=224)$ & 2,78 & 1,64 & $1-5$ \\
Con padres y hermanos/as $(n=219)$ & 2,57 & 1,43 & $1-5$ \\
Con otra persona adulta $(n=223)$ & 2,06 & 1,30 & $1-5$ \\
Solo o sola $(n=245)$ & 2,20 & 1,02 & $1-5$ \\
\hline
\end{tabular}

\section{¿Qué Hacen Niños y Niñas Costarricenses en Edad Preescolar Mientras Ven Televisión?}

Con el propósito de realizar un primer acercamiento al tipo de andamiaje parental ofrecido durante el visionado televisivo, se solicitó a cada persona cuidadora indicar la frecuencia con que realizaba distintas actividades en torno a los contenidos televisivos. La Tabla 4 describe estas distintas actividades, mostrando que la conversación durante el programa es la actividad más frecuentemente utilizada, seguida por el juego. Por último, acompañar al niño sin hablar o jugar con él fue la estrategia reportada como menos frecuente por las madres y padres de la muestra.

Tabla 4

Frecuencia Promedio de Uso de Actividades de Andamiaje Parental durante el Visionado Televisivo Conjunto

\begin{tabular}{|c|c|c|c|}
\hline Tipo de actividad de andamiaje & Media & $D E$ & Rango \\
\hline Conversa con el niño sobre contenido del programa $(n=272)$ & 4,08 & 0,87 & $1-5$ \\
\hline $\begin{array}{l}\text { Conversa con el niño sobre cosas que aparecen en el programa relacionados con } \\
\text { eventos de la vida real }(n=270)\end{array}$ & 3,96 & 0,97 & $1-5$ \\
\hline $\begin{array}{l}\text { Conversa con el niño sobre otras cosas que no tienen que ver con lo que están viendo } \\
(n=267)\end{array}$ & 3,18 & 1,13 & $1-5$ \\
\hline Juega con el niño sobre cosas del programa mientras lo ven $(n=266)$ & 2,79 & 1,11 & $1-5$ \\
\hline Juega con el niño sobre cosas del programa después de verlo $(n=267)$ & 2,73 & 1,05 & $1-5$ \\
\hline $\begin{array}{l}\text { Juega con el niño sobre cosas diferentes a lo que pasa en el programa mientras lo ven } \\
(n=270)\end{array}$ & 2,70 & 1,16 & $1-5$ \\
\hline Acompaña al niño sin hablar o jugar con él $(n=260)$ & 2,43 & 1,10 & $1-5$ \\
\hline
\end{tabular}

\section{Discusión}

El propósito del Estudio 1 fue identificar características básicas del visionado televisivo en niños y niñas costarricenses en edad preescolar a través de una encuesta. Según los reportes de padres y madres, niños y 
niñas ven principalmente programas animados, ya sea con personajes animados o humanos. Además, consumen poca televisión adulta, lo que podría sugerir que están mirando programas que se adecúan a su nivel de desarrollo (Hsin et al., 2014). En su mayoría, las personas cuidadoras participantes reportaron las mayores frecuencias en el uso de canales de servicio de cable, especializados en programación infantil animada. Además, es claro que el consumo televisivo es mayor durante los fines de semana, cuando los niños y niñas no asisten a los centros educativos o de cuido.

Resultados sobre el contexto de uso indicaron que, en promedio, los niños y niñas ven la televisión acompañados casi siempre, siendo la madre o el padre quien los acompaña la mayoría de esas veces. Sin embargo, también se reportó que miraban la televisión solos, aunque esto ocurre en menor medida. En conjunto, estos hallazgos son importantes ante evidencia previa donde se sugiere que los niños y niñas asignan una mayor cantidad de recursos cognitivos cuando sus figuras cuidadoras están presentes durante el visionado televisivo (Fidler et al., 2010; Rasmussen et al., 2016; Strouse \& Troseth, 2014). Por ello, podría concluirse que en las familias participantes existen las condiciones mínimas para que tome lugar un acompañamiento parental que facilita la comprensión de contenidos y el posible aprendizaje a partir de ellos.

Sin embargo, surgen algunas limitaciones en el estudio realizado que no permiten asegurar tal conclusión. Primeramente, dado que la medida utilizada es de autorreporte, la deseabilidad social podría estar jugando un rol en la frecuencia de acompañamiento parental reportada durante el visionado televisivo. En segundo lugar, surge la duda de cómo comprendieron las personas cuidadoras encuestadas el término acompañamiento. Si bien este podría entenderse como la acción conjunta y sostenida del niño o niña y persona cuidadora de prestar atención al mismo estímulo y compartir sobre su contenido a través de gestos y lenguaje verbal, también podría entenderse como solamente estar en la misma habitación mientras el niño mira la televisión, sin necesariamente atender exclusivamente al contenido televisivo que está siendo consumido por el niño o niña. Este último escenario concuerda con la manera en que hallazgos previos han caracterizado el cuido materno, predominante en el contexto cultural costarricense, donde las madres usualmente dirigen su atención hacia el niño o niña, a la vez que atienden otras actividades y otras personas en el contexto inmediato (Rosabal-Coto, 2012).

Entre las actividades que se realizan durante el visionado conjunto, la conversación que vincula de manera directa o indirecta los contenidos del programa proyectado es la que reporta mayor frecuencia de uso. Como tal, de este hallazgo se desprenden varias implicaciones. Una de ellas es que deja en evidencia que la conversación entre madres y padres con sus hijos e hijas sobre contenidos televisivos es familiar y común en la muestra. Además, sugiere la necesidad de indagar de una manera más detallada cuáles son las características de este tipo de conversaciones, con el fin de determinar cuántos de los intentos comunicativos de padres y madres se refieren al contenido televisivo y de qué manera lo hacen. El Estudio 2 se dedicó a abordar esta pregunta de investigación.

\section{Estudio 2}

\section{Método}

\section{Participantes}

Se recurrió a un muestreo no probabilístico por conveniencia. La muestra incluyó 17 díadas conformadas por madres y sus hijos e hijas con edades entre 2 años 10 meses y 4 años 8 meses (edad media $=3$ años y 9 meses, $D E=6,45$ meses, rango $=34-56$ meses). Uno de los casos estuvo conformado por el niño y su hermano gemelo, mientras que en otro caso estuvo presente el hermano menor del niño participante.

Se contactó a la directora de un centro de cuido ubicado en el mismo municipio en el que se encuentra la Universidad de Costa Rica, para que valorara la posibilidad de invitar a las familias del centro a formar parte del estudio. Todas las díadas fueron contactadas a través del mismo centro de cuido y ninguna participó en el Estudio 1.

Los criterios de inclusión utilizados para conformar esta muestra fueron: (a) asistir al centro de cuido, (b) tener entre 2,5 y 5 años y (c) no contar con un diagnóstico de dificultades del desarrollo, de lenguaje, visión o audición al momento de la recolección de datos. La información sobre dicho diagnóstico se obtuvo a través del reporte docente. En caso de presencia de diagnóstico, no se envió la información sobre el estudio a la familia. La mayoría de la muestra estuvo conformada por madres que contaban con secundaria completa y, en menor medida, por madres con estudios universitarios o técnicos (ver Tabla 5). Al revisar los cuestionarios sobre 
información sociodemográfica, se observaron unos pocos valores perdidos. Por tanto, las frecuencias variaron a través de los ítems que se presentan a continuación.

\section{Tabla 5}

Estadísticas Descriptivas de Variables Sociodemográficas de la Muestra del Estudio 2

\begin{tabular}{lc}
\hline \multicolumn{1}{c}{ Variable } & Frecuencia (porcentaje) \\
\hline Sexo del niño & $17(100,0)$ \\
Femenino & $5(29,5)$ \\
Masculino & $12(70,5)$ \\
Nivel educativo de la madre & $17(100,0)$ \\
Primaria completa & $7(41,1)$ \\
Secundaria completa & $3(17,8)$ \\
Estudios técnicos & $6(35,2)$ \\
Estudios universitarios & $1(5,9)$ \\
Personas con las que vive el niño & $17(100,0)$ \\
Con la madre & $17(100,0)$ \\
Con el padre & $2(11,7)$ \\
Con hermanos mayores & $9(52,9)$ \\
Con hermanos menores $(n=16)$ & $1(6,2)$ \\
Condición laboral de la madre & $17(100,0)$ \\
Trabaja fuera de la casa & $17(100,0)$ \\
Condición laboral del padre & $14(100,0)$ \\
Trabaja fuera de la casa & $13(92,8)$ \\
No trabaja fuera de la casa & $1(7,2)$ \\
\hline
\end{tabular}

${ }^{1}$ Categorías no excluyentes.

\section{Instrumentos}

Ficha Sociodemográfica. En este instrumento se consultó a la madre sobre la conformación del hogar del niño o niña (e.g., personas con las que vive, edad), así como datos de la madre y el padre (e.g., condición laboral).

Observación videograbada. Se grabó con una cámara el vídeo y audio de la interacción de las diadas mientras veían el capítulo del programa en una televisión. La cámara se colocó en una esquina de la habitación donde se encontraba la televisión, enfocando el sillón en el que se encontraban el niño y la madre. Una experimentadora encendió la cámara y salió de la habitación hasta que los y las participantes avisaran que habían finalizado la actividad.

\section{Procedimiento}

Los protocolos y el consentimiento informado de este estudio fueron sometidos a revisión del Comité Ético Científico de la Universidad de Costa Rica. Luego de contar con el visto bueno de la directora del centro de cuido, se envió una invitación a las familias de niños y niñas que cumplieran con los criterios de inclusión para participar. Las familias interesadas devolvieron la invitación con información de contacto. Se les realizó una llamada telefónica para clarificar dudas sobre el estudio y se acordó una cita para que la familia visitara las instalaciones del Instituto de Investigaciones Psicológicas de la Universidad de Costa Rica durante junio y julio del año 2016 y así llevar a cabo la sesión de recolección de información con dos integrantes del equipo investigador.

Esta única sesión inició con la lectura, aclaración y firma del consentimiento informado. Posteriormente, una integrante del equipo investigador se sentó con el niño o la niña a jugar un juego de palabras que consistió en la Subprueba de Vocabulario de Dibujos Woodcock-Muñoz (Schrank et al., 2005), mientras la madre completaba la ficha de información sociodemográfica. Con ambas actividades, fue posible facilitar la 
familiarización de niños, niñas y madres con las investigadoras. Para efectos de la presente investigación, solamente la información de la ficha sociodemográfica fue tomada en cuenta. No se consideraron los puntajes de la prueba de lenguaje.

Como tercera y última actividad, se realizó la tarea de visionado televisivo conjunto entre la madre y el niño. Para esta actividad, se entregó la siguiente instrucción a las madres: "Nos interesa conocer cómo interactúan las familias mientras observan un programa de televisión. Para esto, queremos solicitarle que observe a continuación un episodio de un programa infantil junto con su hijo o hija. El programa dura 12 minutos. La interacción será grabada en audio y vídeo. Por favor, actúe como lo hace usualmente en el hogar. Yo voy a salir de la habitación y ustedes me avisan cuando ya estén listos." Se procedió, entonces, a proyectar el capítulo 1 de la serie Charlie y Lola, titulado "Nunca jamás me comeré un tomate" (Child \& Taylor, 2006). Durante el episodio, el hermano mayor (Charlie) debe darle de comer a su hermana pequeña (Lola). Sin embargo, la niña no desea comer lo que se le ofrece. Ante esto, Charlie la ayuda a ver los alimentos de una forma más divertida con el fin de que los consuma.

La serie Charlie y Lola (Carrington, 2006-2013) fue escogida por ser poco conocida en el contexto costarricense. Su selección se logró luego de ser evaluada junto a otras dos series de televisión por parte de tres de jueces. Cada juez emitió su criterio sobre distintos rubros, que fueron evaluados a partir de una escala Likert de 5 puntos, desde 1 (completamente en desacuerdo) hasta 5 (completamente de acuerdo). Los rubros fueron: (a) atractivo de la temática, (b) longitud del episodio, (c) presencia de una estructura narrativa clara, (d) una única historia en el episodio, (e) cantidad apta de personajes, (f) contexto apropiado para niños y niñas costarricenses, (g) presencia de una moraleja, (h) predominio de intercambios verbales sobre no verbales e (i) presencia de diálogos cortos.

$\mathrm{Al}$ finalizar la visita, los niños y niñas participantes recibieron un libro de colorear como retribución de su participación. Las madres recibieron un folleto con recomendaciones sobre cómo utilizar las TIC para promover el desarrollo temprano.

\section{Codificación}

Las conversaciones fueron transcritas literalmente para su respectiva codificación y se emplearon las convenciones del sistema minCHAT (MacWhinney, 2000). El sistema de codificación aplicado se basó en literatura previa (Barr et al., 2008; Strouse et al., 2013), utilizando el enunciado como la unidad de análisis. Los enunciados se codificaron a partir del uso de categorías de análisis organizadas en dos distintos niveles. Las categorías de cada nivel fueron exclusivas y excluyentes. El primer nivel se centró en especificar las características estructurales de la conversación, identificando la función de los enunciados a partir de las siguientes 12 categorías:

Pregunta Abierta. Requiere que se provea información más allá de sí/no. Incluye preguntas sobre qué, cuándo, cómo, dónde, por qué (e.g., ¿Qué están haciendo?).

Pregunta Cerrada. Pregunta que puede ser respondida con un simple sí o no. Incluye preguntas de elección (e.g., ¿Son papas fritas o una barra de chocolate?).

Declaración. Incluyen referentes individuales como, por ejemplo, perro, gato o eso es verde. También incluye enunciados más largos como los sellos están subiendo y bajando por la rampa.

Confirmación. Es la retroalimentación positiva o negativa que da la madre en relación a la expresión o comportamiento anterior del niño, como sí, es cierto, uhum. Incluye asentir con la cabeza.

Corrección. Enunciado que corrige el enunciado del niño. Por ejemplo, no en respuesta al niño diciendo sí, sí en respuesta al niño diciendo no, no me parece que sea así o no creo. Incluye negar con la cabeza.

Aclaración. Proveer o solicitar la correcta pronunciación de una palabra o solicitar al niño que repita un enunciado que la madre no pudo escuchar o entender.

Verbalización Interactiva. Comentarios sobre la forma en que el niño interactúa con el vídeo o bien sugerencias acerca de cómo debe actuar el niño respecto al vídeo, como estás bailando o vamos a aplaudir.

Pregunta de Llenar. Comentarios que pretenden que el niño complete la oración, como iLas verduras y las frutas te hacen muy...? 
Enunciado Conversacional. Interjecciones o expresiones cuyo propósito principal era mantener el flujo de la conversación. Por ejemplo, ¿En serio?, ¿Verdad?, ¿Viste? al final de un enunciado y ¿̇Ajá? luego de que el niño interviene. También se codificaron aquí las afirmaciones de las afirmaciones.

Llamado Atencional. Son los intentos de la madre para obtener la atención de los niños verbalmente por medio del uso de expresiones como mire, vea eso o repitiendo la información.

Verbalización Inclasificable. Abarcó verbalizaciones que no se pudieron transcribir y datos que no se encontraron en ninguna categoría. Aquí se incluye el habla materna dirigida a hermanos, así como el habla del hermano.

Verbalización No Referente al Programa. Son verbalizaciones que no tienen relación con el contenido del vídeo o son ambiguas respecto de si la madre estaba refiriéndose al contenido del vídeo o a un objeto del lugar.

Para el segundo nivel, las preguntas abiertas, las preguntas cerradas y las declaraciones se clasificaron según su contenido. Solamente estas tres categorías fueron codificadas en este segundo nivel pues presentaron las mayores frecuencias y ofrecieron suficiente información para identificar su contenido. Para este segundo nivel de codificación se utilizaron las siguientes siete categorías:

Descripción. Enunciado que nombra un ítem en el vídeo o solicita información al niño. Por ejemplo, la mariposa, las nubes.

Predicción/Inferencia. Enunciados que predicen qué va a suceder en la historia, integran o establecen relaciones entre eventos de la historia o presentan una conclusión. Por ejemplo, ¿Qué crees que va a pasar? o ¿Es eso cierto? Se incluyen, además, preguntas sobre las razones que justifican una emoción y que no están descritas en el programa.

Relacional. Es información brindada por el interlocutor que va más allá del contexto inmediato del vídeo. Incluye solicitar o proporcionar información sobre una conexión entre las experiencias de los niños y el vídeo. Por ejemplo, usted sí come pescado con puré.

Evaluación. Son solicitudes o juicios realizados por el interlocutor respecto al vídeo, como esto es muy divertido o uno tiene que comer de todo. También incluye evaluaciones hechas a los personajes del programa o a los elementos que este presenta, como el tomate es delicioso.

Repetición. Un enunciado en el cual la madre repite lo que le preguntó anteriormente al niño.

Descripción con Llamado Atencional. Enunciados que llaman la atención del interlocutor a alguna parte del programa y que acompañan una descripción. Por ejemplo, vea las zanahorias donde caen.

Comodín. Son respuestas del interlocutor que no proporcionan ninguna información nueva, como no sé, porque sí.

La participación de los niños y niñas en las conversaciones se clasificó en las mismas categorías. Para asegurar la calidad en el proceso de codificación, la tercera y cuarta autoras codificaron de manera independiente el $25 \%$ de las interacciones. Esto correspondió a las conversaciones de cuatro díadas que fueron escogidas aleatoriamente del total de la muestra. La comparación de ambas codificaciones independientes indicó un índice de acuerdo de Kappa de Cohen = 0,92, lo cual se considera un nivel excelente (Fleiss, 1981). Los desacuerdos fueron identificados y resueltos. Posteriormente, cada evaluadora codificó la mitad de las transcripciones restantes.

\section{Análisis de Datos}

Análisis estadísticos descriptivos fueron realizados con base en las frecuencias de uso de las distintas categorías de análisis.

\section{Resultados}

En las Tablas 6 a 9 se describen las frecuencias promedio de las distintas categorías observadas en los dos niveles de codificación. El reporte de aquellas categorías descritas en la sección anterior pero no observadas en la muestra fue omitido en las tablas. 


\section{Andamiaje Parental}

La frecuencia de producción de enunciados por parte de las madres se caracteriza por una importante variabilidad. Las frecuencias promedio de la tipología de enunciados utilizados por las madres según su estructura se describen en la Tabla 6. De las categorías de interés, se observa que las madres mayormente ofrecieron declaraciones sobre el contenido televisivo (ver Anexo), seguidas por el uso de llamados atencionales y preguntas, tanto abiertas como cerradas. De manera importante, utilizaron también enunciados conversacionales que intentaban involucrar al niño en la discusión del programa de una manera general, sin dar mayores lineamientos sobre cómo contribuir.

\section{Tabla 6}

Frecuencias Promedio de los Tipos de Enunciado Maternos

Producidos durante el Visionado Televisivo $(\mathrm{n}=17)$

\begin{tabular}{lrrc}
\hline \multicolumn{1}{c}{ Categoría } & Media & $D E$ & Rango \\
\hline Total de enunciados & 85,00 & 86,71 & $9-288$ \\
Preguntas abiertas & 5,06 & 6,01 & $0-18$ \\
Preguntas cerradas & 5,41 & 3,39 & $1-12$ \\
Declaraciones & 35,94 & 28,09 & $1-88$ \\
Confirmaciones & 3,00 & 2,97 & $0-8$ \\
Correcciones & 0,82 & 0,88 & $0-3$ \\
Aclaraciones & 0,65 & 0,99 & $0-4$ \\
Verbalizaciones interactivas & 1,18 & 3,37 & $0-14$ \\
Preguntas de llenar & 0,06 & 0,24 & $0-1$ \\
Enunciados conversacionales & 6,06 & 5,84 & $0-22$ \\
Llamados atencionales & 7,76 & 9,01 & $0-34$ \\
Verbalizaciones inclasificables & 13,00 & 8,93 & $3-28$ \\
Verbalizaciones no referentes al programa & 17,00 & 17,74 & $0-55$ \\
\hline
\end{tabular}

La codificación por contenido permitió dar una mirada más detallada a las preguntas y las declaraciones. La Tabla 7 muestra que las descripciones en forma de preguntas abiertas y declaraciones fueron bastante frecuentes, al igual que comentarios relacionales en forma de preguntas cerradas y declaraciones. Las evaluaciones en forma de declaraciones fueron también altamente utilizadas por las madres de la muestra. Por el contrario, subcategorías como las predicciones o inferencias y las evaluaciones en forma de pregunta, que intentaban involucrar al niño y a la niña, fueron bastante infrecuentes en las conversaciones.

\section{Participación Infantil}

Los niños y las niñas participantes produjeron un promedio de 20 enunciados sobre el programa, también con una gran variabilidad entre ellos (Tabla 8). Sus intervenciones consistieron principalmente en declaraciones, seguidas por enunciados conversacionales y preguntas abiertas. Al analizar las declaraciones en mayor detalle (Tabla 9), se observa que estas consistieron, en la mayoría de los casos, en descripciones de lo que ocurre en el programa, seguidas por comentarios relacionales que conectaban los contenidos del programa con la vida del niño o niña. Nuevamente, se observa la baja frecuencia de declaraciones referidas a predicciones o inferencias sobre la trama de la historia o sobre preguntas referentes a los estados emocionales de los personajes. Al observar los tipos de pregunta que realizaron los niños y niñas participantes, se observa que estas son abiertas y orientadas a obtener descripciones maternas sobre los contenidos. 
Tabla 7

Frecuencias Promedio de los Tipos de Contenido en las Preguntas Abiertas, Preguntas Cerradas y Declaraciones Maternas Producidas durante el Visionado Televisivo $(\mathrm{n}=17)$

\begin{tabular}{lrrl}
\hline \multicolumn{1}{c}{ Subcategoría } & Media & $D E$ & Rango \\
\hline Preguntas abiertas & & & \\
Descripción & 3,29 & 3,65 & $0-10$ \\
Predicción/inferencia & 0,41 & 1,06 & $0-4$ \\
Relacional & 0,71 & 1,57 & $0-6$ \\
Evaluación & 0,06 & 0,24 & $0-1$ \\
Repetición & 0,53 & 0,80 & $0-2$ \\
Descripción con llamado atencional & 0,06 & 0,24 & $0-1$ \\
Preguntas cerradas & & & \\
Descripción & 0,59 & 0,61 & $0-2$ \\
Predicción/inferencia & 0,06 & 0,24 & $0-1$ \\
Relacional & 4,24 & 2,92 & $0-11$ \\
Evaluación & 0,18 & 0,52 & $0-2$ \\
Repetición & 0,35 & 0,70 & $0-2$ \\
Descripción con llamado atencional & 0,00 & - & 0 \\
Declaraciones & & & \\
Descripción & 14,24 & 10,28 & $1-31$ \\
Predicción/inferencia & 2,24 & 2,58 & $0-8$ \\
Relacional & 5,88 & 4,76 & $0-13$ \\
Evaluación & 8,35 & 9,32 & $0-27$ \\
Comodín & 0,41 & 0,61 & $0-2$ \\
Descripción con llamado atencional & 4,82 & 6,10 & $0-17$ \\
\hline
\end{tabular}

Tabla 8

Frecuencias Promedio de los Tipos de Enunciado Producidos por los Niños y Niñas durante el Visionado Televisivo $(\mathrm{n}=17)$

\begin{tabular}{lrrl}
\hline \multicolumn{1}{c}{ Categoría } & Media & $D E$ & Rango \\
\hline Total de enunciados & 20,40 & 10,41 & $5-38$ \\
Preguntas abiertas & 1,35 & 1,80 & $0-5$ \\
Preguntas cerradas & 0,59 & 1,06 & $0-4$ \\
Declaraciones & 15,71 & 9,27 & $2-33$ \\
Enunciados conversacionales & 1,94 & 2,22 & $0-8$ \\
Llamados atencionales & 0,88 & 0,93 & $0-3$ \\
Verbalizaciones inclasificables & 7,76 & 8,12 & $0-22$ \\
Verbalizaciones no referentes al programa & 7,76 & 7,21 & $0-24$ \\
\hline
\end{tabular}


Tabla 9

Frecuencias Promedio de los Tipos de Contenido en las Preguntas Abiertas, Preguntas Cerradas y Declaraciones Producidas por los Niños y Niñas durante el Visionado Televisivo $(\mathrm{n}=17)$

\begin{tabular}{lccc}
\hline \multicolumn{1}{c}{ Subcategoría } & Media & $D E$ & Rango \\
\hline Preguntas abiertas & & & \\
$\quad$ Descripción & 1,06 & 1,39 & $0-5$ \\
$\quad$ Predicción/inferencia & 0,18 & 0,72 & $0-3$ \\
$\quad$ Relacional & 0,12 & 0,48 & $0-2$ \\
Preguntas cerradas & & & \\
$\quad$ Descripción & 0,24 & 0,43 & $0-1$ \\
$\quad$ Predicción/inferencia & 0,18 & 0,72 & $0-3$ \\
$\quad$ Relacional & 0,18 & 0,52 & $0-2$ \\
Declaraciones & & & \\
$\quad$ Descripción & 7,35 & 5,84 & $1-24$ \\
$\quad$ Predicción/inferencia & 0,71 & 0,98 & $0-3$ \\
$\quad$ Relacional & 5,82 & 5,10 & $0-2$ \\
$\quad$ Evaluación & 0,88 & 1,49 & $0-5$ \\
Repetición & 0,06 & 0,24 & $0-1$ \\
Comodín & 0,41 & 0,61 & $0-2$ \\
Descripción con llamado atencional & 0,47 & 0,80 & $0-2$ \\
\hline
\end{tabular}

\section{Discusión}

El Estudio 2 caracterizó la participación de la persona cuidadora y el niño y la niña en la conversación ocurrida al mirar una serie de televisión infantil. El primer hallazgo es que las madres presentaron un repertorio discursivo variado, que incluyó todas las categorías de análisis. Si bien no todas las madres usaron la totalidad de las categorías, la muestra total sí lo hizo. Entre las categorías más empleadas, referentes al contenido televisivo, están las preguntas abiertas, las declaraciones y las confirmaciones. La presencia de estas estrategias discursivas caracteriza el estilo de conversación altamente elaborado en el contexto de las conversaciones sobre experiencias personales pasadas (Carmiol \& Sparks, 2014; Fivush, 2019). Además, su uso materno durante la reminiscencia se ha encontrado relacionado con distintos logros del desarrollo infantil (Waters et al., 2019). Futuros estudios podrían indagar la relación entre el uso materno de estas estrategias elaboradas durante el visionado conjunto y el nivel de comprensión de contenidos de niños y niñas.

Las madres emplearon las declaraciones en mayor medida, seguidas por las preguntas cerradas y posteriormente por las preguntas abiertas. Las declaraciones fueron aplicadas principalmente para ofrecer descripciones de lo que sucedía en el programa, ya sea por iniciativa de la madre o ante las preguntas de niños y niñas. Las preguntas cerradas fueron empleadas en mayor medida para hacer referencia al programa en tanto se relacionaba con la vida del niño o la niña. A diferencia, las preguntas abiertas funcionaron principalmente para solicitar a niños y niñas que describieran aspectos del programa.

Las declaraciones también fueron expresadas por las madres para mencionar aspectos del programa relacionados con la vida del niño o bien para ofrecer evaluaciones de los contenidos del programa, como el comportamiento de los personajes. El uso frecuente de evaluaciones referentes al comportamiento de personajes es consistente con lo observado en otros contextos de conversación. En un análisis de interacciones durante la lectura compartida entre madres costarricenses y alemanas con sus hijos e hijas preescolares, Carmiol y Schröder (2019) encontraron que ambos grupos de madres, pero especialmente las costarricenses, usaron un estilo conversacional centrado en la conducta de los personajes. Dicho estilo se ha identificado previamente como una estrategia para enseñar a niños y niñas sobre maneras apropiadas de comportarse, y su presencia parece ser más frecuente en contextos culturales de orientación interdependiente, donde metas de socialización como el buen comportamiento y la obediencia son altamente valoradas (Eisenberg, 1999; Wang \& Fivush, 2005). 
Llama la atención, además, que las predicciones/inferencias fueron en general poco frecuentes y se produjeron en mayor medida en forma de declaración y no de pregunta. Esta baja frecuencia de predicciones/inferencias es consistente con lo observado en otros contextos de interacción, como la lectura compartida (e.g., DeTemple, 2001) y la resolución de tareas de orden físico (e.g., Crowley et al., 2001), donde la mayoría de las intervenciones adultas se circunscriben al ámbito del aquí y el ahora, refiriéndose principalmente a la descripción de contenidos, ya sea del libro o de los objetos poco familiares en discusión. En menor medida se utilizan estrategias discursivas abstractas, como predicciones o inferencias, que se remiten al uso del lenguaje descontextualizado y cuya frecuencia como parte del andamiaje parental se ha visto asociada con la promoción de distintos aspectos del desarrollo infantil (Benjamin et al., 2010; Mol et al., 2008).

Una posible explicación del alto uso de descripciones es que el programa expuesto no promoviera el uso de estrategias más abstractas, basadas en lenguaje descontextualizado. Otra posibilidad es que las madres de la muestra no acostumbren a utilizar estas estrategias durante el visionado televisivo. Hallazgos previos sugieren que el uso de estrategias abstractas es infrecuente por parte de padres y madres, aun cuando la conversación de las díadas verse en torno a estímulos complejos (e.g., un zoótropo) (Crowley et al., 2001). Este resultado apoya la segunda explicación. Sin embargo, resulta importante que esfuerzos futuros profundicen en el tema, debido a que resultados previos sugieren que la calidad de los contenidos televisivos a los que se ven expuestos niños y niñas es un factor fundamental para asegurar la promoción del desarrollo infantil (Rasmussen et al., 2016), lo que también podría afectar la calidad del andamiaje parental.

$\mathrm{Al}$ igual que las madres, los niños y niñas produjeron declaraciones en mayor medida. Estas consistieron en su mayoría en descripciones de lo que ocurría en el programa, seguido por comentarios que conectaban los contenidos del programa con la vida del niño o niña. Nuevamente, se observa la baja frecuencia de declaraciones referentes a predicciones o inferencias sobre la trama de la historia o preguntas que se refieran a los estados mentales o emocionales de los personajes.

Considerando el déficit de transferencia que tiene lugar a edades tempranas en el aprendizaje por medio de pantallas, Lerner y Barr (2015) indicaron que el involucramiento parental hace que los niños y niñas puedan transferir de mejor manera los contenidos observados en la pantalla al mundo real, en comparación a cuando lo realizan sin hablar o jugar. A partir de esto, podría considerarse que el uso predominante de declaraciones por parte de las madres, niños y niñas para describir el programa es una herramienta útil para hacerle frente a este déficit, con el fin de facilitar una mejor comprensión del contenido observado. Es importante que futuros estudios exploren esta relación.

En cuanto a las limitaciones, evaluar el visionado conjunto en un ambiente controlado, como se llevó a cabo en la presente investigación, puede diferir de la interacción que ocurre en el contexto cotidiano del hogar. Resulta importante que estudios futuros aborden el tema de investigación aquí desarrollado a través del uso de herramientas como el sistema Language Environment Analysis (LENA; Gilkerson et al., 2017), por medio de las cuales es posible acceder el ambiente lingüístico natural sin las restricciones que presenta un escenario de laboratorio.

\section{Discusión General}

La discusión sobre el efecto del visionado televisivo por parte de niñas y niños pequeños ha sido un tema de debate durante décadas. En este debate se han formulado posiciones diversas, que van desde aquellas que resaltan el efecto negativo de la exposición a la televisión en el desarrollo infantil (Reid Chassiakos et al., 2016), hasta otras que sugieren sus beneficios en el desarrollo temprano (Anderson \& Hanson, 2010). En un número considerable de estudios en torno al tema solamente se ha tomado en cuenta la cantidad de exposición a la televisión por parte de los niños y las niñas, dejando de lado la calidad de la experiencia. Sin embargo, un elemento que resulta relevante conocer antes de identificar el efecto de las TIC en el desarrollo infantil es la calidad de la interacción que ocurre en torno a su uso. El propósito de los dos estudios aquí descritos fue precisamente proveer información sobre el contexto de uso de la televisión en el hogar por parte de niños y niñas preescolares, y la calidad del andamiaje parental ofrecido durante el visionado televisivo conjunto. Para esto, se utilizaron dos distintas aproximaciones metodológicas, a saber: un cuestionario de auto-reporte dirigido a personas cuidadoras, y la observación directa de madres mirando un programa con sus hijos e hijas en un ambiente de laboratorio.

Los hallazgos del Estudio 1 indicaron que, según lo reportado por padres y madres, los niños y niñas miran la televisión acompañados casi siempre y en muy pocas ocasiones lo hacen en solitario. Asimismo, 
indicaron que ellos mismos son la principal compañía de los niños y las niñas durante la actividad, y que usualmente conversaban sobre el contenido del programa, o bien relacionaban su contenido con las experiencias personales del niño y la niña. Estos resultados son alentadores, pues parecen indicar que las personas cuidadoras supervisan lo que sus hijos e hijas preescolares ven en la televisión. El Estudio 2 apoyó los resultados del Estudio 1 al evidenciar que las madres participantes en efecto entablaron intercambios conversacionales en torno a los contenidos televisivos mostrados. Además, se centraron en el uso de declaraciones orientadas a describir los contenidos del programa, mientras que su uso de estrategias cognitivamente demandantes (predicciones e inferencias) fue escaso.

El análisis del visionado televisivo y de su efecto en el desarrollo temprano requiere la consideración de diversos factores intervinientes. Entre ellos se encuentran la edad del niño o niña, el tipo de programación al que se ven expuestos y expuestas y la calidad del andamiaje parental que se brinda durante la exposición (Kostyrka-Allchorne et al., 2017). Los resultados aquí reportados contribuyen al acervo de conocimiento sobre el consumo televisivo en la población infantil y la calidad de la interacción que toma lugar cuando este consumo ocurre en compañía de personas cuidadoras. Específicamente, se observan notables coincidencias en las características de las conversaciones observadas durante el visionado televisivo y aquellas previamente documentadas en la literatura para el caso de contextos como la lectura compartida (DeTemple, 2001) o bien la resolución de tareas de orden físico (Crowley et al., 2001). En todos los casos, el intercambio natural entre las personas cuidadoras y los niños y niñas suele remitirse a la conversación de elementos ubicados en el contexto inmediato del aquí y el ahora (DeTemple, 2001) y en menor medida se utiliza el habla descontextualizada en forma de predicciones e inferencias, que presentan una mayor demanda cognitiva para el niño y niña.

Ante estas similitudes entre contextos de interacción, surge la pregunta de si, al igual que para el caso de la lectura compartida (Mol et al., 2008) y la resolución de tareas de orden físico (Benjamin et al., 2010; Fender \& Crowley, 2007; Tompkins et al., 2017) es posible capacitar a las personas cuidadoras en el uso de estrategias conversacionales de alta demanda cognitiva durante el visionado televisivo conjunto. Igualmente, surge la pregunta de si incentivar el uso de estas estrategias en las personas cuidadoras durante el visionado televisivo es una vía efectiva para promover ganancias cognitivas y de aprendizaje en niños y niñas. Considerando la alta cobertura del servicio televisivo en los hogares costarricenses (MICITT, 2016) y en América Latina (Gobbi \& Machado Filho, 2015) y tomando en cuenta el acceso limitado a recursos educativos como literatura infantil para una gran parte de la niñez latinoamericana (Instituto Nacional de Estadística y Censos et al., 2018; Strasser \& Lissi, 2009), es importante que futuros estudios experimentales se den a la tarea de evaluar si incentivar el andamiaje parental de calidad durante el visionado televisivo conjunto es efectivo en la promoción de la comprensión de contenidos y el aprendizaje temprano.

\section{Referencias}

Anderson, D. R. \& Hanson, K. G. (2010). From blooming, buzzing confusion to media literacy: The early development of television viewing. Developmental Review, 30(2), 239-255. https://doi.org/1016/j.dr.2010.03.004

Barr, R. (2013). Memory constraints on infant learning from picture books, television, and touchscreens. Child Development Perspectives, 7(4), 205-210. https://doi.org/10.1111/cdep.12041

Barr, R., Zack, E., Garcia, A. \& Muentener, P. (2008). Infants' attention and responsiveness to television increases with prior exposure and parental interaction. Infancy, 13(1), 30-56. https://doi.org/10.1080/15250000701779378

Benjamin, N., Haden, C. A. \& Wilkerson, E. (2010). Enhancing building, conversation, and learning through caregiver-child interactions in a children's museum. Developmental Psychology, 46(2), 502-515. https://doi.org/10.1037/a0017822

Blankson, A. N., O'Brien, M., Leerkes, E. M., Calkins, S. D. \& Marcovitch, S. (2015). Do hours spent viewing television at ages 3 and 4 predict vocabulary and executive functioning at age 5? Merrill-Palmer Quarterly, 61(2), 264-289. https://doi.org/10.13110/merrpalmquar1982.61.2.0264

Brito, N., Barr, R., McIntyre, P. \& Simcock, G. (2012). Long-term transfer of learning from books and video during toddlerhood. Journal of Experimental Child Psychology, 111(1), 108-119. https://doi.org/10.1016/j.jecp.2011.08.004

Carmiol, A. M. \& Schröder, L. (2019). Emotion talk during mother-child reminiscing and book sharing and children's socioemotional competence: Evidence from Costa Rica and Germany. Culture and Brain, 7(2), 126-174. https://doi.org/10.1007/s40167-019-00078-x

Carmiol, A. M. \& Sparks, A. (2014). Narrative development across cultural contexts. Finding the pragmatic in parent-child reminiscing. En D. Matthews (Ed.), Pragmatic development in first language acquisition (pp. 279-294). John Benjamins Publishing Company. https://doi.org/10.1075/tilar.10.16car

Carrington, M. (Productor ejecutivo). (2006-2013). Charlie y Lola [Serie de TV]. BBC.

Child. L. (Escritor) \& Taylor, K. (Director). (13 de febrero de 2006). Nunca jamás me comeré un tomate (Temporada 1, Episodio 1) [Episodio de serie de TV]. En M. Carrington (Productor Ejecutivo), Charlie y Lola. BBC.

Crawley, A. M., Anderson, D. R., Wilder, A., Williams, M. \& Santomero, A. (1999). Effects of repeated exposures to a single episode of the television program Blue's Clues on the viewing behaviors and comprehension of preschool children. Journal of Educational Psychology, 91(4), 630-637. https://doi.org/10.1037/0022-0663.91.4.630 
Crowley, K., Callanan, M. A., Jipson, J. L., Galco, J., Topping, K. \& Shrager, J. (2001). Shared scientific thinking in everyday parentchild activity. Science Education, 85(6), 712-732. https://doi.org/10.1002/sce.1035

DeTemple, J. M. (2001). Parents and children reading books together. En D. K. Dickinson \& P. O. Tabors (Eds.), Beginning literacy with language: Young children learning at home and school (pp. 31-52). Paul H. Brookes.

Eisenberg, A. R. (1999). Emotion talk among Mexican American and Anglo American mothers and children from two social classes. Merrill-Palmer Quarterly, 45(2), 267-284. www.jstor.org/stable/23093678

Fender, J. G. \& Crowley, K. (2007). How parent explanation changes what children learn from everyday scientific thinking. Journal of Applied Developmental Psychology, 28(3), 189-210. https://doi.org/10.1016/i.appdev.2007.02.007

Fidler, A. E., Zack, E. \& Barr, R. (2010). Television viewing patterns in 6- to 18-month-olds: The role of caregiver-infant interactional quality. Infancy, 15(2), 176-196. https://doi.org/10.1111/j.1532-7078.2009.00013.x

Fivush, R. (2019). Family narratives and the development of an autobiographical self: Social and cultural perspectives on autobiographical memory. Routledge. https://doi.org/10.4324/9780429029158

Fivush, R. \& Fromhoff, F. A. (1988). Style and structure in mother child conversations about the past. Discourse Processes, 11(3), 337355. https://doi.org/10.1080/01638538809544707

Fleiss, J. L. (1981). Statistical methods for rates and proportions. John Wiley \& Sons.

Gilkerson, J., Richards, J. A., Warren, S. F., Montgomery, J. K., Greenwood, C. R., Kimbrough Oller, D., Hansen, J. H. L. \& Paul, T. D. (2017). Mapping the early language environment using all-day recordings and automated analysis. American Journal of SpeechLanguage Pathology, 26(2), 248-265. https://doi.org/10.1044/2016_AJSLP-15-0169

Gobbi, M. C. \& Machado Filho, F. (2015). Televisão e mídias digitais na América Latina: um cenário em construção [Televisión y medios digitales en América Latina: un escenario en construcción]. INTERCOM: Revista Brasileira de Ciências da Comunicação, 38(1), 85107. https://doi.org/10.1590/1809-5844201514

Hsin, C. -T., Li, M. -C. \& Tsai, C. -C. (2014). The influence of young children's use of technology on their learning: A review. Journal of Educational Technology \& Society, 17(4), 85-99. www.jstor.org/stable/jeductechsoci.17.4.85

Instituto Nacional de Estadística y Censos, Ministerio de Salud \& Fondo de las Naciones Unidas para la Infancia Costa Rica. (2018). Encuesta de mujeres, niñez y adolescencia (EMNA) 2018 [Conjunto de datos]. https://www.inec.cr/documento/encuesta-de-mujeresninez-y-adolescencia-2018-emna

Kostyrka-Allchorne, K., Cooper, N. R. \& Simpson, A. (2017). The relationship between television exposure and children's cognition and behaviour: A systematic review. Developmental Review, 44, 19-58. https://doi.org/10.1016/i.dr.2016.12.002

Lauricella, A. R., Wartella, E. \& Rideout, V. J. (2015). Young children's screen time: The complex role of parent and child factors. Journal of Applied Developmental Psychology, 36, 11-17. https://doi.org/10.1016/j.appdev.2014.12.001

Lerner, C. \& Barr, R. (2015). Screen sense: Setting the record straight-Research-based guidelines for screen use for children under 3 years old. ZERO TO THREE, 35(4), 1-10. https://nyspep.org/application/files/4015/0005/1044/Screen_Sense_-White_Paper.pdf

Lin, L. -Y., Cherng, R. -J., Chen, Y. -J. (Yung-Jung), Chen, Y. -J. (Yi-Jen) \& Yang, H. -M. (2015). Effects of television exposure on developmental skills among young children. Infant Behavior and Development, 38, 20-26. https://doi.org/10.1016/j.infbeh.2014.12.005

Linebarger, D. L., Barr, R., Lapierre, M. A. \& Piotrowski, J. T. (2014). Associations between parenting, media use, cumulative risk, and children's executive functioning. Journal of Developmental \& Behavioral Pediatrics, 35(6), 367-377. https://doi.org/10.1097/DBP.0000000000000069

Linebarger, D. L. \& Piotrowski, J. T. (2009). TV as storyteller: How exposure to television narratives impacts at-risk preschoolers' story knowledge and narrative skills. British Journal of Developmental Psychology, 27(1), 47-69. https://doi.org/10.1348/026151008X400445

MacWhinney, B. (2000). The CHILDES project: Tools for analyzing talk. Transcription format and programs (3a ed.). Lawrence Erlbaum.

McCabe, A. \& Peterson, C. (1991). Getting the story: A longitudinal study of parental styles in eliciting oral personal narratives and developing narrative skill. En A. McCabe \& C. Peterson (Eds.), Developing narrative structure (pp. 217-253). Lawrence Erlbaum.

Ministerio de Ciencia, Tecnología y Telecomunicaciones. (2016). Acceso y uso de los servicios de telecomunicaciones en Costa Rica, 2015. Gobierno de Costa Rica. https://www.micitt.go.cr/portaldos/images/imagenes_noticias/12-23-2016-MICITT-presenta-los-resultadosde-la-Encuesta-de-Acceso-y-Uso-de-los-Servicios-de-Telecomunicaciones-en-Costa-Rica-2015/Acceso-y-uso-de-los-servicios-detelecomunicaciones-en-costa-rica-2015.pdf

Mol, S. E., Bus, A. G., de Jong, M. T. \& Smeets, D. J. H. (2008). Added value of dialogic parent-child book readings: A meta-analysis. Early Education and Development, 19(1), 7-26. https://doi.org/10.1080/10409280701838603

Rasmussen, E. E., Keene, J. R., Berke, C. K., Densley, R. L. \& Loof, T. (2017). Explaining parental coviewing: The role of social facilitation and arousal. Communication Monographs, 84(3), 365-384. https://doi.org/10.1080/03637751.2016.1259532

Rasmussen, E. E., Shafer, A., Colwell, M. J., White, S., Punyanunt-Carter, N., Densley, R. L. \& Wright, H. (2016). Relation between active mediation, exposure to Daniel Tiger's Neighborhood, and US preschoolers' social and emotional development. Journal of Children and Media, 10(4), 443-461. https://doi.org/10.1080/17482798.2016.1203806

Reid Chassiakos, Y., Radesky, J., Christakis, D., Moreno, M. A., Cross, C. \& Council on Communications and Media. (2016). Children and adolescents and digital media. Pediatrics, 138(5), Artículo e20162593. https://doi.org/10.1542/peds.2016-2593

Rosabal-Coto, M. (2012). Creencias y prácticas de crianza: el estudio del parentaje en el contexto costarricense. Revista Costarricense de Psicología, 31(1-2), 65-100. http://www.rcps-cr.org/openjournal/index.php/RCPs/article/view/10

Schrank, F. A., McGrew. K. S., Ruef, M. L., Alvarado, C. G., Muñoz-Sandoval, A. F. \& Woodcock, R. W. (2005). Batería III WoodcockMuñoz: Assessment service bulletin number 1-Overview and technical supplement. Riverside.

Strasser, K. \& Lissi, M. R. (2009). Home and instruction effects on emergent literacy in a sample of Chilean kindergarten children. Scientific Studies of Reading, 13(2), 175-204. https://doi.org/10.1080/10888430902769525

Strouse, G. A., O'Doherty, K. \& Troseth, G. L. (2013). Effective coviewing: Preschoolers' learning from video after a dialogic questioning intervention. Developmental Psychology, 49(12), 2368-2382. https://doi.org/10.1037/a0032463

Strouse, G. A. \& Troseth, G. L. (2014). Supporting toddlers' transfer of word learning from video. Cognitive Development, $30,47-64$. https://doi.org/10.1016/j.cogdev.2014.01.002

Tompkins, V., Bengochea, A., Nicol, S. \& Justice, L. M. (2017). Maternal inferential input and children's language skills. Reading Research Quarterly, 52(4), 397-416. https://doi.org/10.1002/rrq.176

Valkenburg, P. M. (2004). Children's responses to the screen: A media psychological approach. Routledge. https://doi.org/10.4324/9781410610331

Van Evra, J. (2004). Television and child development. Third Edition. Routledge. https://doi.org/10.4324/9781410610447

Wang, Q. \& Fivush, R. (2005). Mother-child conversations of emotionally salient events: Exploring the functions of emotional reminiscing in European-American and Chinese families. Social Development, 14(3), 473-495. https://doi.org/10.1111/j.1467-9507.2005.00312.x 
Waters, T. E. A., Camia, C., Facompré, C. R. \& Fivush, R. (2019). A meta-analytic examination of maternal reminiscing style: Elaboration, gender, and children's cognitive development. Psychological Bulletin, 145(11), 1082-1102. https://doi.org/10.1037/bul0000211

\section{Anexo}

\section{Extracto de Conversación durante el Visionado Conjunto de Una de las Díadas Participantes}

M: ¿de qué color es esa vaca?

$\mathrm{N}$ : eh, petipolla [petipoa; son las arvejas en Costa Rica].

M: pero, ¿de qué color es la vaca?

$\mathrm{N}$ : verde.

M: verde.

M: ¿y las nubes de qué color son?

$\mathrm{N}$ : verde.

M: verdes.

M: y vea lo que está cayendo.

M: en vez de gotas están cayendo petipoas.

$\mathrm{N}$ : petipoa.

M: ¿ves?

M. son deliciosas.

M: ¿vio como se las come?

M: vea el pajarito.

M: que a pesar que ella diga que no le gustan, ella las termina probando.

M: y son ricos.

M: ¿ve?

M: por eso, todos los alimentos hay que probarlos y no decir que son feos ni que nunca voy a comerlos, porque son ricos.

M: ¿sí?

M: ¿qué es eso?

M: ¿qué es eso?

$\mathrm{N}$ : papas.

M: una papa gigante.

M: ¿te gusta el puré?

M: ¿sí?

$\mathrm{N}$ : [el niño asiente].

Nota. $\mathrm{M}=$ madre, $\mathrm{N}=$ niño.

Fecha de recepción: Abril de 2019.

Fecha de aceptación: Enero de 2021. 